\title{
Uma espécie asiática invade a paisagem do sul do Brasil
}

\section{An Asian species invades the landscape of southern Brazil}

\author{
Recebido em: 18/06/2018 \\ Aceito em: 18/12/2018 \\ Aline Beatriz Pacheco Carvalho ${ }^{1}$ \\ Judite Sansonde Bem² \\ Maurício Pereira Almerão ${ }^{3}$ \\ Cristina Vargas Cademartori ${ }^{4}$
}

\begin{abstract}
Resumo:
Este ensaio visual versa sobre a temática da invasão biológica como consequência da ação antrópicae seus impactosnegativos ao patrimônio natural. Os registros fotográficos foram obtidos entre março e abril de 2018 no município de Itati, Rio Grande do Sul, organizados através de legendas explicativas e discutidos a partir de fontes orais e bibliográficas. As fotografias evidenciam a presença da espécie exótica invasora Hoveniadulcis (uva-do-japão) na unidade de conservação Reserva Biológica Estadual Mata Paludosa e em áreas limítrofes, revelando a situação de fragilidade dos últimos remanescentes de Mata Paludosa no Rio Grande do Sul.
\end{abstract}

Palavras-chave: Hoveniadulcis; Espécie exótica invasora; Patrimônio natural.

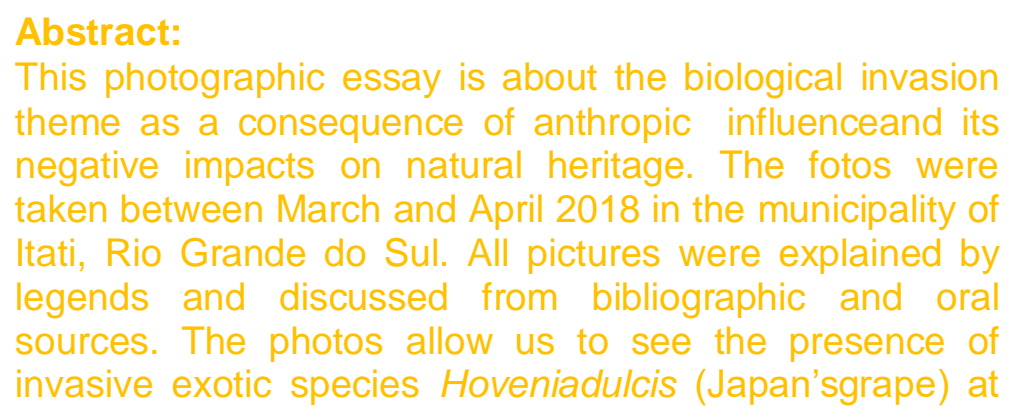

${ }^{1}$ Bolsista CAPES, doutoranda em Memória Social e Bens Culturais na Universidade La Salle. Bióloga no Centro de Estudos Ambientais Eco-Terrenão - Glorinha, RS. pacheco.carvalho@gmail.com

2Doutora Professora Adjunta II da Universidade LaSalle, PPG em Memória Social e Bens Culturais, Mestrado em Avaliação de Impactos Ambientais, Curso de Gestão Financeira da Universidade LaSalle. judite.bem@unilasalle.edu.br

${ }^{3}$ Doutor Professor Assistente III da Universidade La Salle, Mestrado em Avaliação de Impactos Ambientais, Curso de Ciências Biológicas na Universidade La Salle. mauricio.almerao@unilasalle.edu.br

4 Doutora Professora Adjunta II da Universidade La Salle, PPG em Memória Social e Bens Culturais, Mestrado em Avaliação de Impactos Ambientais, Curso de Ciências Biológicas na Universidade La Salle. cristina.cademartori@unilasalle.edu.br 


\section{Invasões biológicas}

Nas últimas décadas, as Invasões Biológicas ou, simplesmente, o estudo de Espécies Exóticas Invasoras (EEl's), têm ocupado lugar de destaque na lista de preocupações atuais sobre o meio ambiente. A Convenção sobre a Diversidade Biológica $(\mathrm{CDB})^{5}$ atualmente trata as EEl's como uma das principais inquietações relacionadas, por exemplo, à perda de biodiversidade. Neste sentido, o Rio Grande do Sul estabelece normas de controle, entre outras providências, em Portaria SEMA n 79 de 31 de outubro de $2003 .^{6}$

As espécies introduzidas em um ecossistema diferente daquele no qual surgiram e evoluíram são denominadas exóticas (VALÉRY, 2008). Por sua vez, as espécies exóticas invasoras (EEl's)são aquelas capazes de se reproduzir e manter populações viáveis nos locais onde foram introduzidas, além de conseguirem se dispersar e ocupar áreas distantes do local original da introdução. Embora a introdução possa ocorrer em qualquer ambiente, somente algumas espécies conseguem se estabelecer e aumentar a taxa de reprodução e dispersão, alcançando, assim, o status de invasoras. Quando as invasoras substituem espécies nativas, o processo é denominadode invasão biológica (MORO, 2012). Ao estabelecerem populações viáveis e se dispersarem, as espécies invasoras causam impactos econômicos, sociais e ambientais negativos nas áreas invadidas (SIMBERLOFF, 2013).

A espécie humana tem contribuído para a dispersão de espécies exóticas,possibilitando a transposição de barreiras naturais pelos mais diversos motivos, principalmente para produção de alimentos e outros usos comerciais. 0

5Decreto Legislativo oㅡ 2, de 1994. Disponível em: http://www.mma.gov.br/informma/item/7513convenção-sobre-diversidade-biológica-cdb

${ }^{6}$ Reconhece a Lista de Espécies Exóticas Invasoras do Estado do Rio Grande do Sul e demais classificações, estabelece normas de controle e dá outras providências. Disponível em: http://www.sema.rs.gov.br/upload/arquivos/201612/23180118-portaria-sema-79-de-2013-especiesexoticas-invasoras-rs.pdf 
problema é que a maior parte das invasões biológicas provoca alterações nos processos ecossistêmicos, tais comomodificações irreversíveis na estrutura das comunidades naturais, motivo pelo qual as EEl's são consideradas responsáveis por boa parte das extinções atuais (GUREVITCH, 2004).

As EEl's não ocupam ou ameaçam apenas as áreas desprotegidas legalmente, visto que inúmeras Unidades de Conservação (UC's) no mundo inteiro têm sofrido as consequências das invasões biológicas (POORTER, 2007), figura 1. Sampaio e Schimidt (2013) descreveram o cenário das invasões biológicas em UC's federais brasileiras. Os autores apontaram que a maior parte das EEl's registradas compreendia plantas (106 das 144 espécies registradas). Muitas das EEl's identificadas, incluindo Hoveniadulcis, estão relacionadas ao hábito de cultivo humano, corroborando a ideia de que as ações antrópicas são vias de introdução e dispersão de EEl's e, por consequência, causas das alterações nas paisagens e patrimônio natural, figura 2.

Figura 1:A Unidade de Conservação.

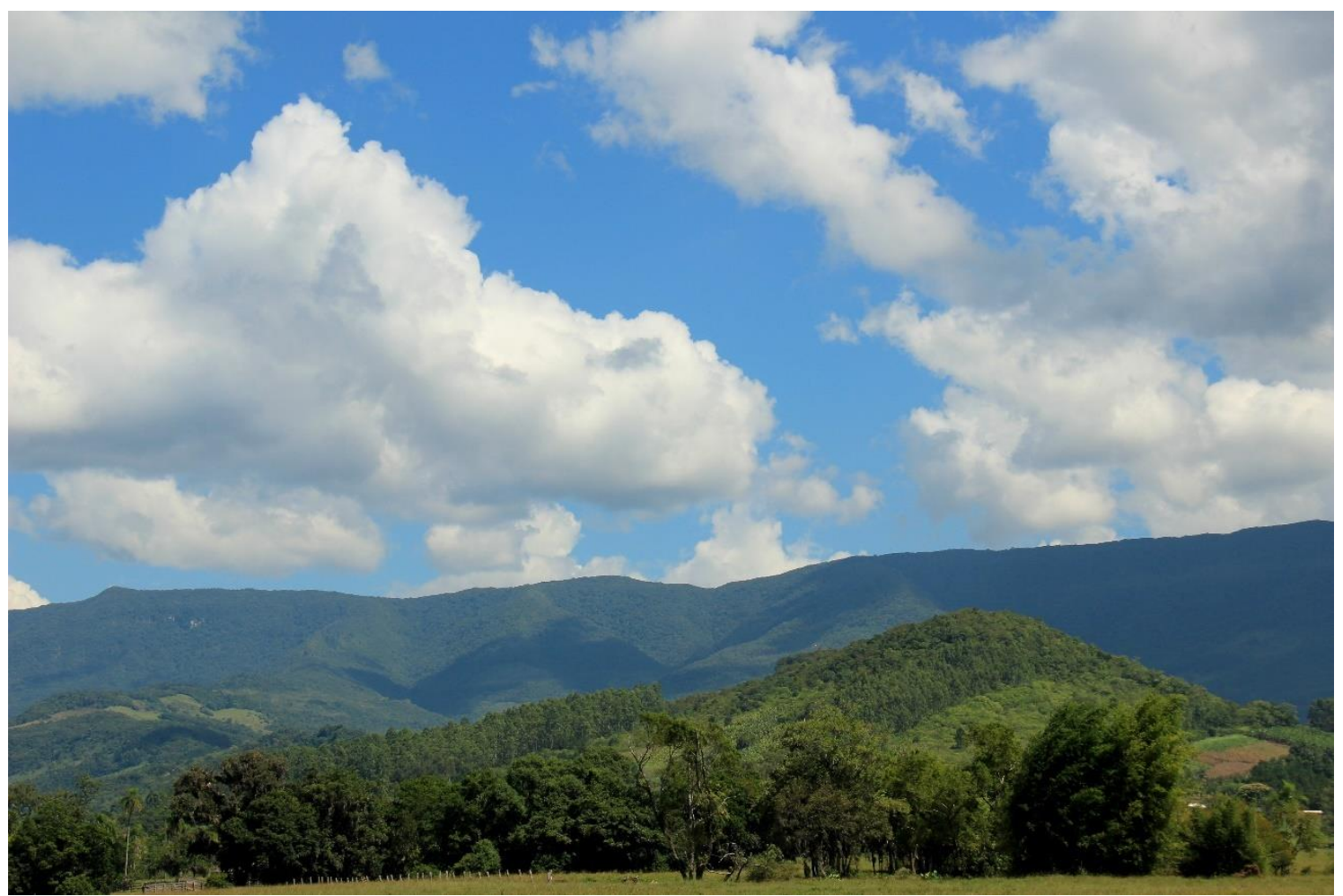

Em Itati, RS, localiza-se a Reserva Biológica Estadual Mata Paludosa (REBIO Mata Paludosa). Criada pelo Decreto Estadual $n^{\circ} 38.972 / 1998$,está inserida no domínio daMata Atlântica e abrange uma área de 272 hectares.Trata-se de uma Unidade de Conservação estratégica, que protege áreas relictuais de transição entre os ambientes de encosta e baixada, abrigando os últimos remanescentes de Mata Paludosa (floresta formada sobre solos bastante úmidos) no estado (VIEIRA, 2008). Intervenções de manejo são realizadas pelos agentes dos órgãos ambientais competentes a fim de manter a integridade 
da fauna e flora nativas. Relatos da gestora da REBIO Mata Paludosa e de moradores locais indicam a presença da espécie exótica invasora Hoveniadulcis no interior da Unidade de Conservação.Local: Itatí, RS. Fonte: Aline B. P. Carvalho, 2018.

Figura 2: A presença.

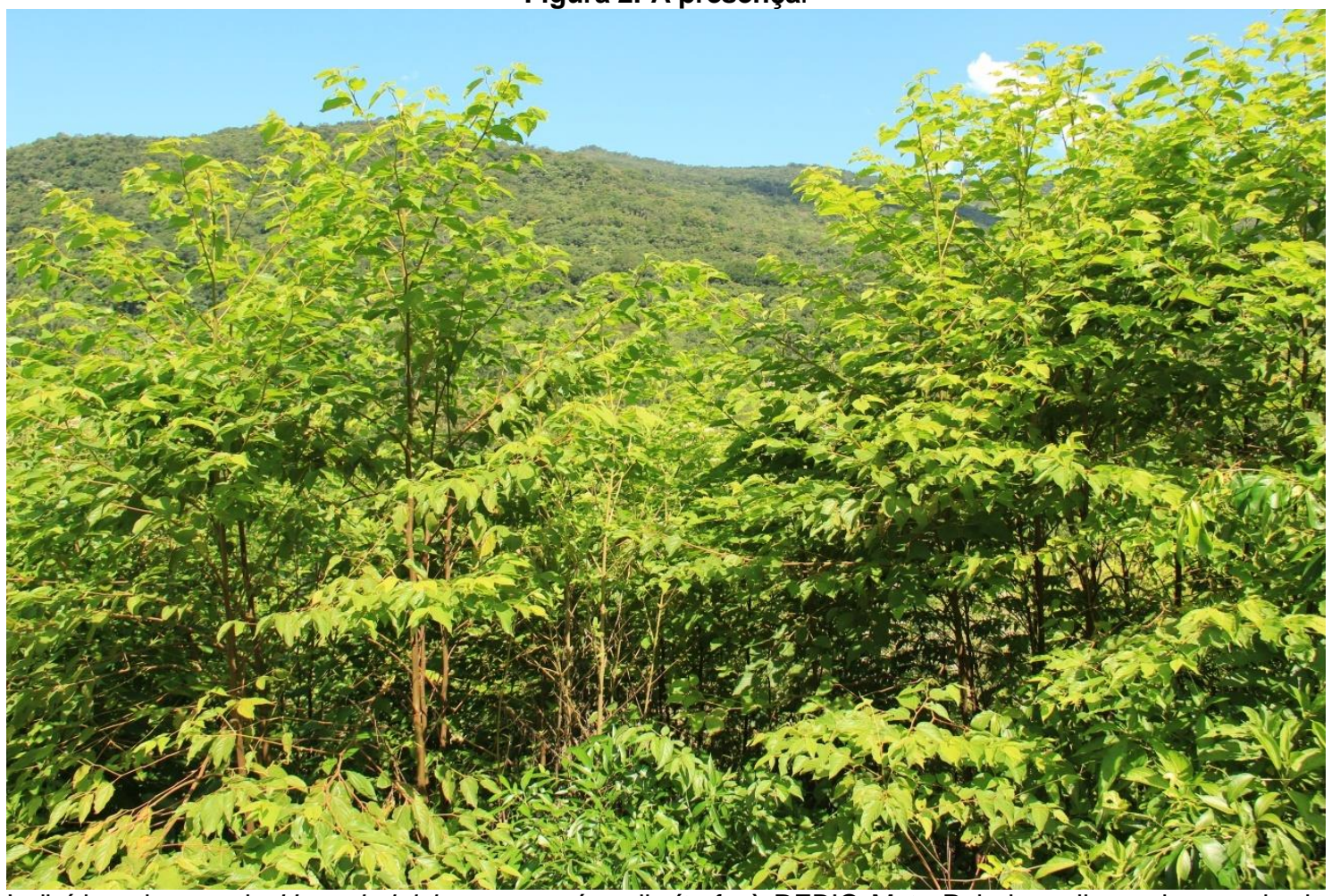

Indivíduos jovens de Hoveniadulcis em uma área limítrofe à REBIO Mata Paludosa, livres do manejo de contenção. Local: Itati, RS. Fonte: Aline B. P. Carvalho, 2018.

\section{Uma espécie asiática no sul do Brasil}

Espécies exóticas invasoras já integrama paisagem de ambientes naturais no Brasil (ZENNI, 2015). A Hoveniadulcis, popularmente conhecida como uva-do-japão, espécie nativa da Ásia, é facilmente observada no sul do Brasil, frequentemente em remanescentes de Floresta Ombrófila Mista (ZENNI, 2015). Esta espécie tem encontrado condições ambientais adequadas para o seu estabelecimento e dispersão em áreas alteradas antropicamente (SCHNEIDER, 2007) (figura3), e em áreas naturais, como a REBIO Mata Paludosa em Itati. Devido à sua rápida propagação e intensa regeneração, é considerada uma invasora que produz descendentes em número muito elevado, que conseguem se dispersar a grandes distâncias da planta matriz, competindo, assim, com as espécies nativas (SCHNEIDER, 2007), figuras 4 e 5. 
Figura 3: Áreas favoráveis.

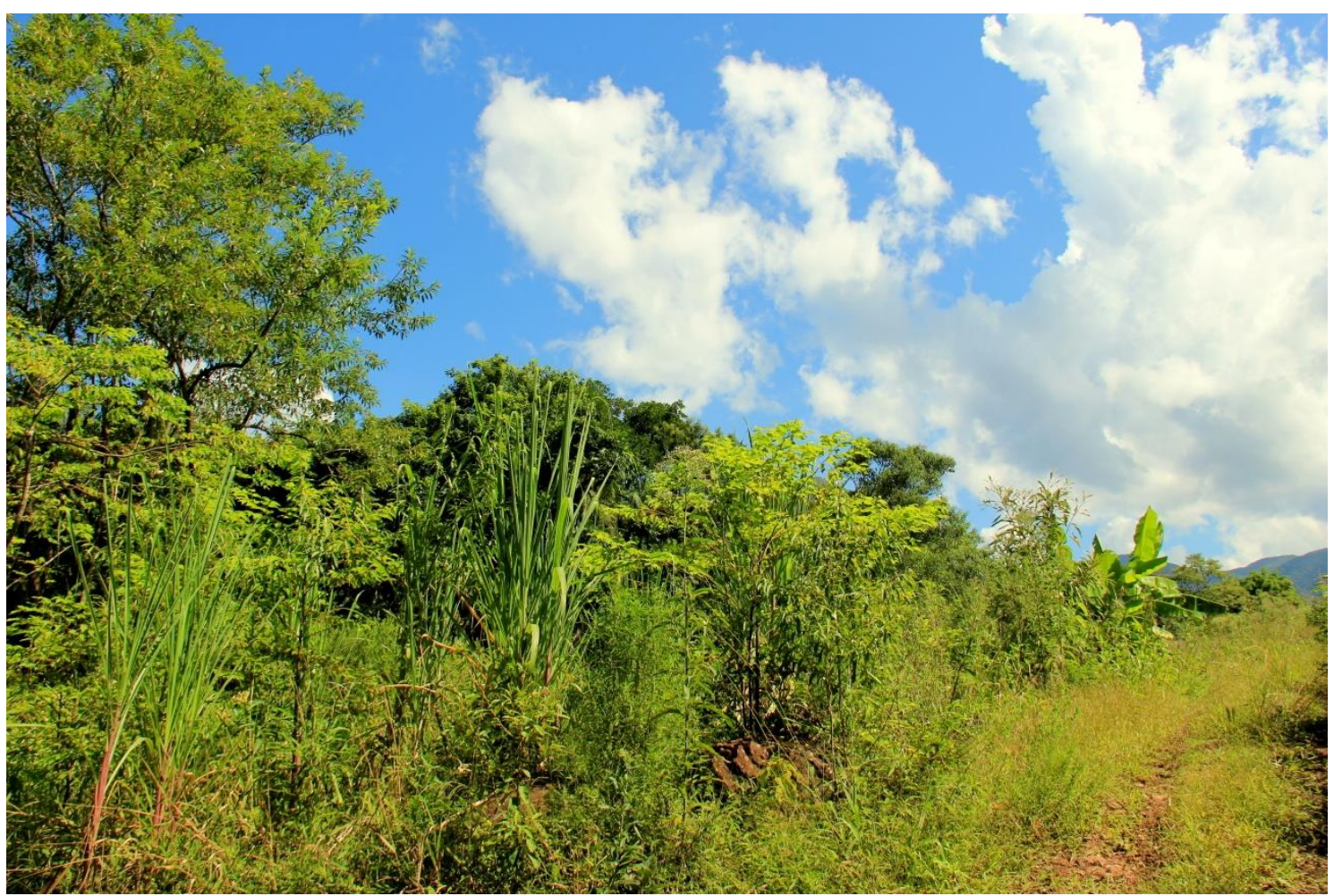

Vista parcial de uma área de cultivo abandonada, localizada em uma propriedade particular em zona limítrofe à REBIO Mata Paludosa. As áreas alteradas pela ação antrópica favorecem o estabelecimento de espécies exóticas invasoras em decorrência da falta de competidores, predadores e parasitas, o que confere vantagens competitivas em relação à flora nativa. A suscetibilidade à invasão quase sempre está associada à própria ação do homem, seja pelo cultivo inicial, abandono do manejo ou pela alteração da dinâmica natural de um ecossistema (ZENNI, 2015). Local: Itatí,RS. Fonte: Aline B. P. Carvalho, 2018. 
Figura 4: A dispersão.

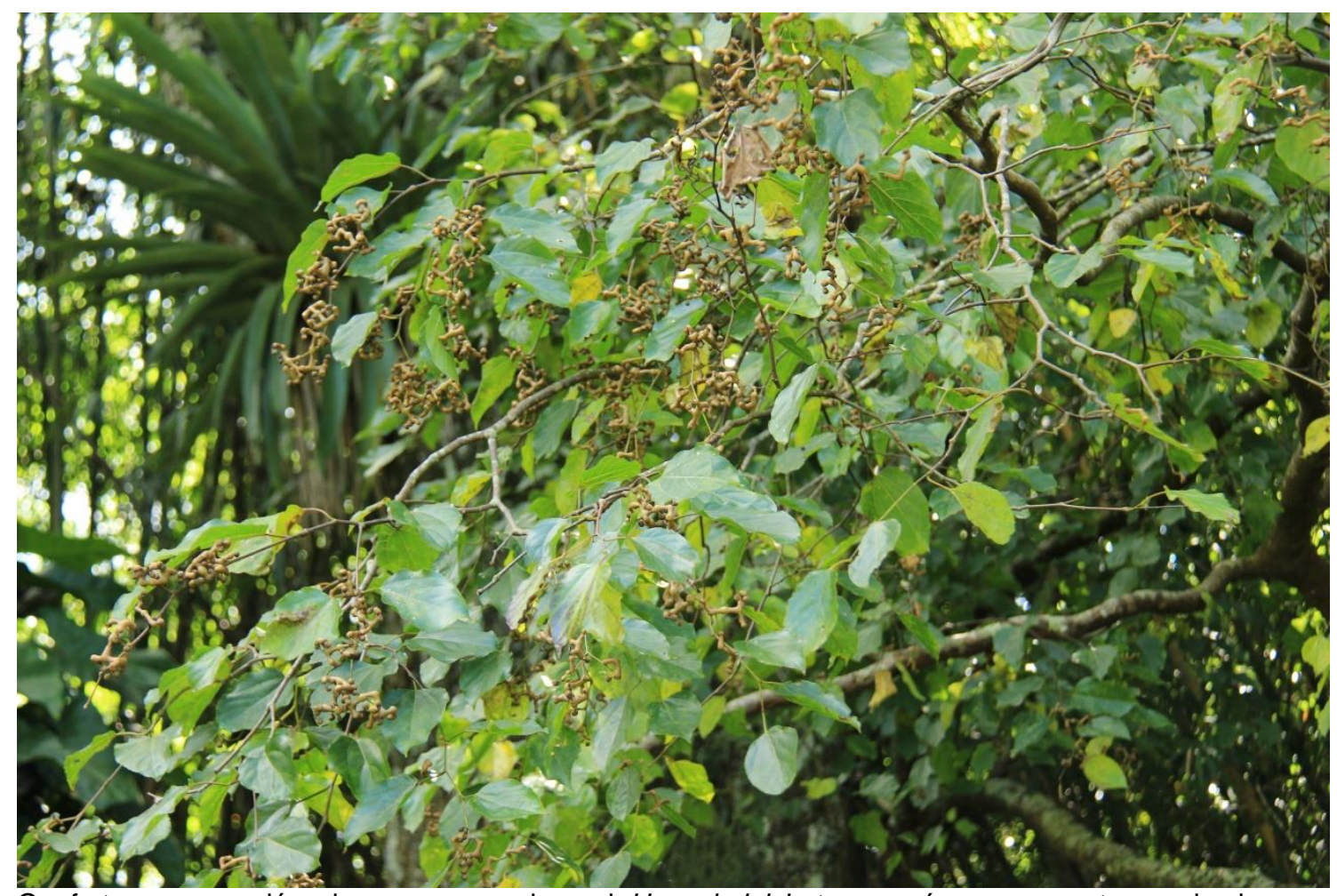

Os frutos com pedúnculo carnoso e doce deHoveniadulcisatraem pássaros e outros animais, que contribuem para a dispersão da planta ao disseminarem suas sementes (GISP, 2005). Local: Itati, RS. Fonte: Aline B. P. Carvalho, 2018. 
Figura 5: 0 estabelecimento e a competição.

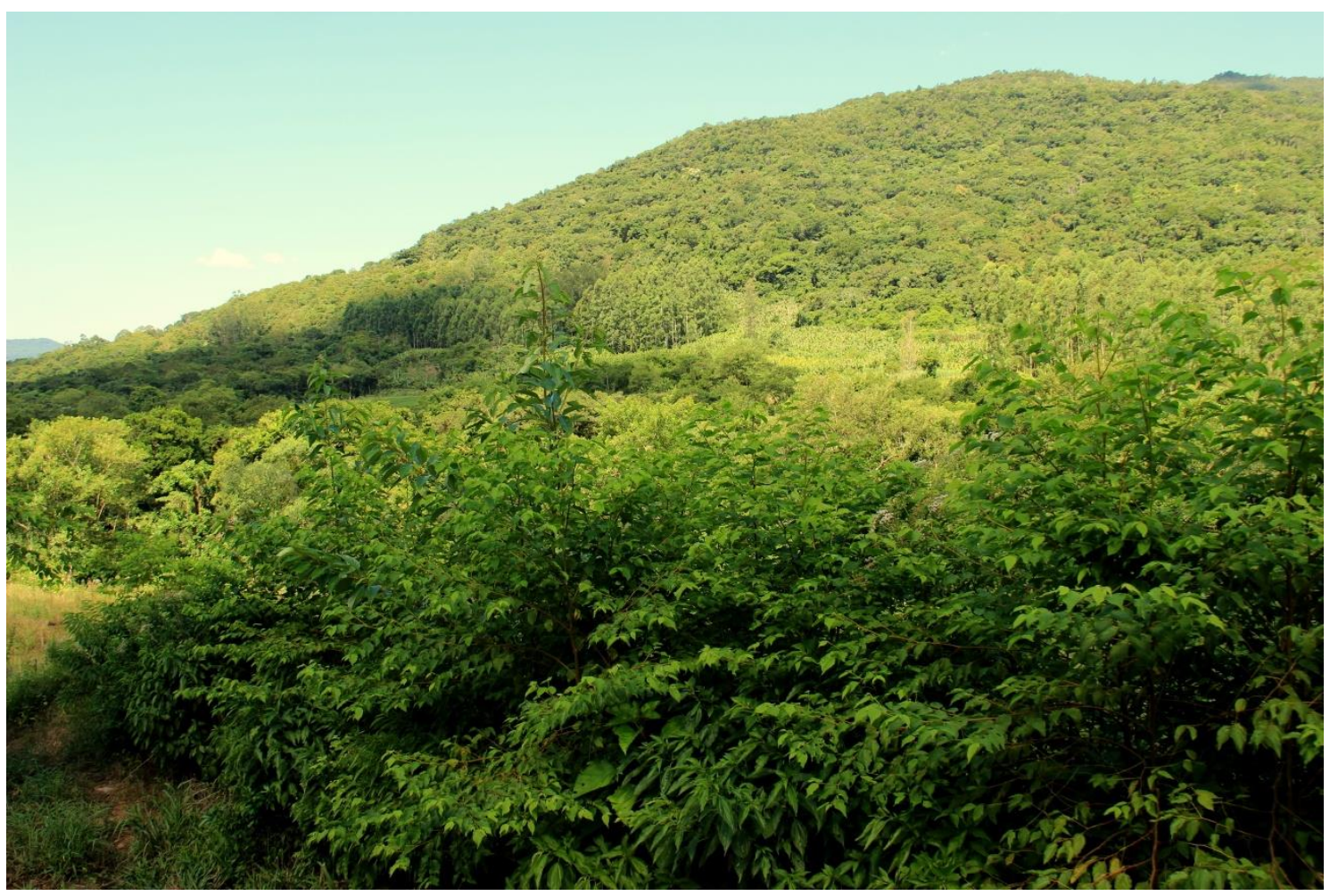

Indivíduos jovens de Hoveniadulcis, espécie exótica invasora que possui a capacidade de produzir muitos descendentes e se dispersar a grandes distâncias da planta matriz (SCHNEIDER, 2007), em área limítrofe à REBIO Mata Paludosa. Local: Itati, RS. Fonte: Aline B. P. Carvalho, 2018.

O histórico da introdução da uva-do-japão em Itati, é incerto.No entanto, estima-se que o cultivo desta espécie e a sua presença na paisagem ocorra desde meados da década de 1970, figura 6.Uma vez estabelecida na paisagem e na ausência de informações sobre os prejuízos ambientais causados pela espécie, a utilização deHoveniadulcis foi difundida e estimulada com diferentes finalidades:

os antigos moradores acreditavam ser uma árvore boa, utilizavam para a madeira e com boa floração para mel. A floração atrai muitas abelhas, já a madeira só pode ser usada para ambientes internos, pois não há resistência para a umidade (...), (P.T. TRISCH, 2018).

Os possíveis impactos negativos desta EEI são desconhecidos pela população local, o que contribui para a existência do cultivo. Atualmente, é fato que a espécie se estabeleceu nesta região (e em outras do sul do Brasil), tornando-se prevalente na paisagem local. 
Figura 6: Presença na paisagem.

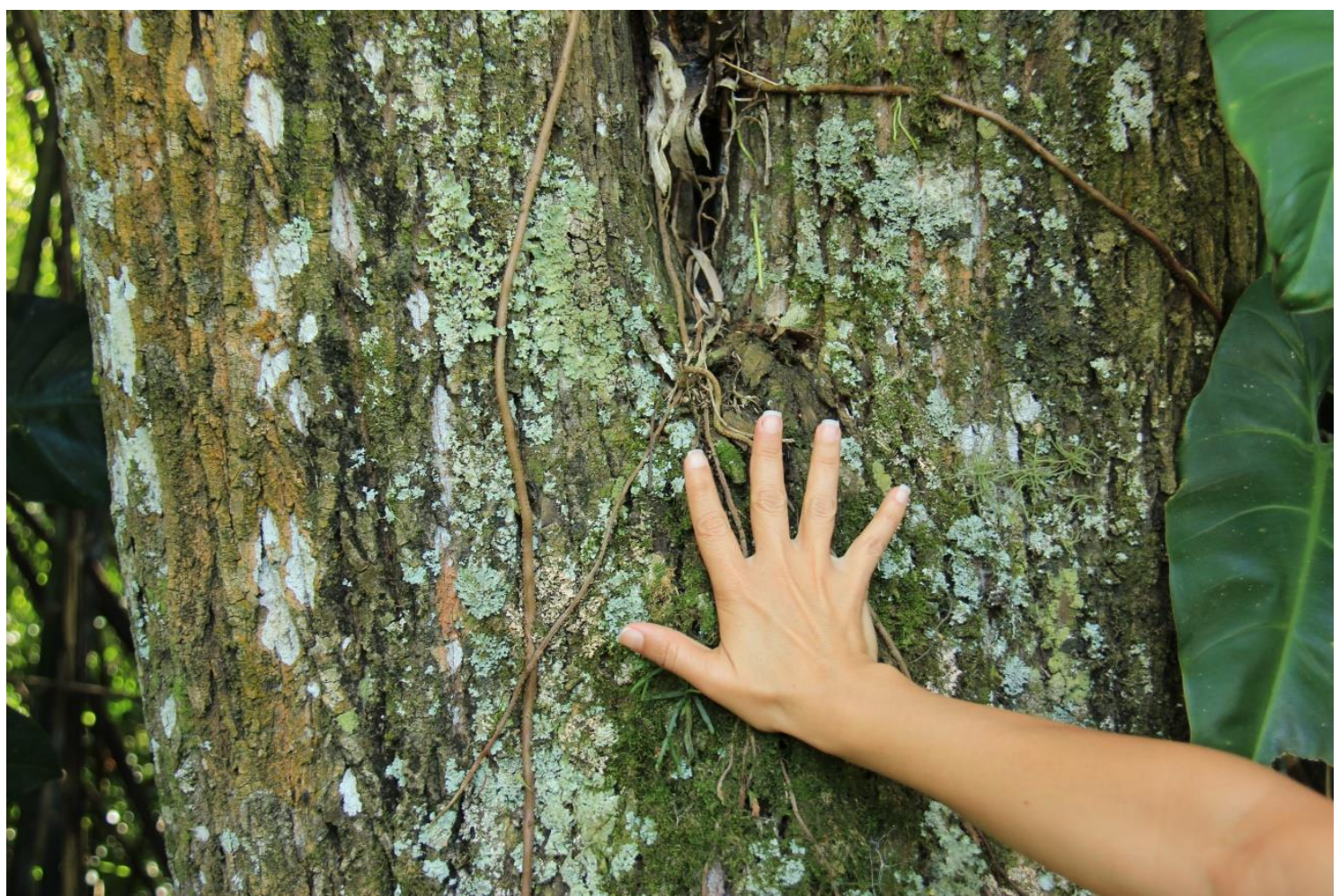

Em detalhe, um indivíduo de Hoveniadulcis de aproximadamente 40 anos de idade que, independentemente da condição exótica e invasora, é preservado por seu valor sentimental, uma vez que remete o proprietário a lembranças familiares e laços afetivos (conforme fonte oral por $P$. T. Trinch, 2018). Relata ele, que acerca de 40 anos atrás o indivíduo ainda jovem foi plantado na propriedade da família, pois naquela época o conhecimento local propagava os benefícios associados ao uso desta espécie, estimulando o seu plantio na região, especialmente por sua contribuição na regeneração de áreas abandonadas e/ou degradadas. Local: Itatí,RS. Fonte: Aline B. P. Carvalho, 2018.

\section{Considerações finais}

Áreas degradadas, alteradas pela ação antrópica e/ou abandonadas são, geralmente, propíciasao estabelecimento de espécies exóticas invasoras em decorrência da baixa biodiversidade e heterogeneidade espacial, da existência de funções ecológicas ainda não supridas e da ausência de "inimigos naturais". Algumas ações intencionais ou práticas erradas de manejo do solo beneficiam as espécies exóticas invasoras, tais como a remoção de vegetação nativa, queimadas, erosão e pastoreio excessivo. Soma-se a isso, a facilidade de deslocamento do homem moderno, que pode transpor barreiras geográficas e conduzir, acidental ou intencionalmente, de um local a outro, espécies que se originaram e evoluíram em 
outras regiões. Por tais razões, os acordos e dispositivos legais nacionais e internacionais, que preveem o controle e a proibição de introdução e soltura deliberada de espécies exóticas, invasoras ou não, são tão importantes.

Inevitavelmente a uva-do-japão já está inserida na paisagem de Itati, tanto nos remanescentes naturais quanto em áreas adjacentes e no interior da REBIO Mata Paludosa. Em se tratando de uma espécie exótica invasora com o potencial de extinguir ou deslocar espécies nativas por competição,são imprescindíveis estudos e pesquisas multidisciplinares visando ao manejo e controle da espécie exótica invasora, e àproposição de alternativaseconômicas aos proprietários rurais que a utilizam para a geração de renda. Desta forma, ações educativas formais e não formais, que promovam o envolvimento da comunidade nos processos e decisões, podem contribuir mais eficazmente para o sucesso de medidas de remediação e/ou manejo adequado de espécies invasoras,conciliando o desenvolvimento econômico e a salvaguardado patrimônio natural. Caso contrário, este processo de homogeneização biótica nos reservará, em um futuro breve, um planeta cada vez mais pobre e semelhante.

\section{Agradecimento}

À Fernanda Schmitt, engenheira agrônoma, analista ambiental da Secretaria Estadual do Meio Ambiente (SEMA-RS) e gestora da REBIO Mata Paludosa, pelo apoio logístico, mobilização e interlocução com a comunidade do município,aos moradores de Itati que contribuíram com a pesquisa, em especial à Eliane R. deS., José M. J. e Pedro T. T., à bióloga Letícia O. C. Escobar pelo apoio e presença nas atividades de campo e à CAPES, pela concessão da bolsa de estudos

\section{Referências}

GISP - Programa Global de Espécies Invasoras. América do Sul invadida. A crescente ameaça das espécies exóticas invasoras. 80p, 2005.

GUREVITCH, J.; PADILLA, D. Are invasive species a major cause of extinctions? TRENDS in Ecology and Evolution, v. 19, n. 9, 2004.

MORO, M. F. et al. Alienígenas na sala: o que fazer com espécies exóticas em trabalhos de taxonomia, florística e fitossociologia?Acta Botanica Brasilica, v. 26, n. 4, p. 991-999, 2012.

POORTER, M.; PAGAS, ULLAH.; MI. Invasive alien species and protected areas: A scoping report. World Bank, IUCN, ISSG, GISP, 93 pp, 2007. 
SAMPAIO, A. B.; SCHMIDT, I. B. Espécies Exóticas Invasoras em Unidades de Conservação Federais do Brasil. In: Número Temático: Diagnóstico e Controle de Espécies Exóticas Invasoras em Áreas Protegidas. Instituto Chico Mendes de Conservação da Biodiversidade. Biodiversidade Brasileira, v. 3, n. 2, p. 32-49, 2013.

SCHNEIDER, A. A. A flora naturalizada no estado do Rio Grande do Sul, Brasil: herbáceas subespontâneas. In: Biociências, Porto Alegre, v. 15, n. 2, p. 257-268, 2007.

VALÉRY, L. et al. In search of a real definition of the biological invasion phenomenon itself. In: Biological Invasions, v. 10, p. 1345-1351, 2008.

VIEIRA, S. F. L. A leitura da paisagem como instrumento para o plano de manejo: Reserva Biológica Estadual Mata Paludosa - Itati/RS. 2008. Dissertação (Mestrado em Geografia) - Universidade Federal do Rio Grande do Sul, Instituto de Geociências. Programa de Pós-Graduação em Geografia. Porto Alegre: UFRGS, 2008.

ZENNI, R. D.; DECHOUM, M. de S. Paisagens Antropizadas e invasão por plantas exóticas. In: PERES, C. A.; BARLOW, J.; GARDENER, T. A.; VIEIRA, I.; C.; G. (Orgs.). Conservação da Biodiversidade em Paisagens Antropizadas do Brasil. Curitiba: Ed. UFPR, 2015. 549 - 564p. 